Research Article

\title{
Forecasting the Agriculture Output Values in China Based on Grey Seasonal Model
}

\author{
Yan Chen $\mathbb{D}$, Li Nu, and Lifeng $W u$ \\ College of Economics and Management, Hebei University of Engineering, Handan 056038, China \\ Correspondence should be addressed to Lifeng Wu; wlf6666@126.com
}

Received 14 March 2020; Revised 30 July 2020; Accepted 12 August 2020; Published 30 August 2020

Academic Editor: Josefa Mula

Copyright (c) 2020 Yan Chen et al. This is an open access article distributed under the Creative Commons Attribution License, which permits unrestricted use, distribution, and reproduction in any medium, provided the original work is properly cited.

\begin{abstract}
The output values for agriculture, forestry, animal husbandry, and fishery are important indicators of agricultural economic development. Therefore, accurately predicting the output values for agriculture, forestry, animal husbandry, and fishery can capture the developmental trend and the optimize the structure. Agriculture, forestry, animal husbandry, and fishery are typical seasonal industries, and thus their output values vary greatly among different seasons. To accurately estimate the seasonal variations in the observed sequence and obtain better prediction results, the output values for agriculture, forestry, animal husbandry, and fishery in different quarters from 2018 to 2021 are predicted and analyzed by using the grey seasonal model (GSM). The results indicated that the prediction accuracy of GSM is relatively high. The output values for the agriculture, forestry, animal husbandry, and fishery as well as their total output value will increase gradually. It is an important achievement of structural reform under the new normal economic situation. In addition, the GSM provides a new method for predicting seasonal data.
\end{abstract}

\section{Introduction}

Agriculture is the foundation of the national economy in China and the basis for human survival and development. Agricultural development is related not only to the quality of people's lives but also to the stability and security of the country. Its output value is important for capturing the trends in agricultural economic development and for adjusting the implementation of policies. Thus, numerous studies have investigated the prediction in various fields of agriculture. In particular, a neural network was optimized with the fruit fly algorithm and used to forecast the agricultural output value for China [1]. A novel two-stage model that combines the grey first-order differential equation $(\mathrm{GM}(1,1))$ model with genetic programming was proposed to forecast the value of agricultural imports [2]. A fully probabilistic approach with dynamical ocean atmosphere models for predicting climate variability at seasonal and interannual time scales was applied for agricultural management prediction [3]. An improved grey forecasting model based on a genetic algorithm was constructed for forecasting agricultural outputs [4]. Grain production in China was predicted by using three hybrid models comprising particle swarm optimization combined with the grey linear power index model, the grey logarithm power model, and the grey parabola power model [5]. The $\operatorname{GM}(1,1)$ model, logistic curve growth model, and exponential growth curve model were used for green agriculture prediction in China [6]. The $\operatorname{GM}(1,1)$ model was also employed for forecasting the agricultural output value and production for various types of agricultural products [7]. A nonlinear autoregressive exogenous model with a neural network and grey system model was integrated to forecast the agricultural areas in China affected by natural disasters [8]. A dynamic equal dimension $\operatorname{GM}(1,1)$ model was constructed for predicting agricultural irrigation water in China [9].

Agriculture plays a significant role in China, and the overall agricultural production capacity has steadily improved because of the continuous optimization and adjustment of agricultural policies during the 40 years of reform and openness. It has been transformed from traditional agriculture with monoculture to the comprehensive 
development of the agriculture, forestry, animal husbandry, and fishery industries. The modern agricultural system is initially established and improved. Among the total output value for agriculture, forestry, animal husbandry, and fishery, the proportion represented by agriculture declined from $80 \%$ in 1978 to $53.8 \%$ in 2017 . By contrast, the proportions accounted for by forestry, animal husbandry, and fishery increased from $3.4 \%, 15 \%$, and $1.6 \%$ in 1978 to $4.3 \%, 26.4 \%$, and $10.7 \%$ in 2017 , respectively (Figure 1). These changes in the output values for agriculture, forestry, animal husbandry, and fishery clearly demonstrate that the agricultural structure has been optimized and adjusted continuously. The development of the agricultural economy depends mainly on these industries, and their output value directly represents the agricultural economy, and thus accurately capturing the developmental trends in the output values for agriculture, forestry, animal husbandry, and fishery is crucial for facilitating reform and upgrading of the agricultural structure. Therefore, predicting the output values for agriculture, forestry, animal husbandry, and fishery is also of great practical importance.

Agriculture-related industries have typical seasonal characteristic, and their output values vary significantly among different quarters. However, few previous studies of agricultural prediction have considered the seasonal variations in the output value. In this study, the quarterly output values of agricultural, forestry, animal husbandry, and fishery are predicted in order to provide technical support for relevant departments, so they can adjust their policies and measures according to seasonal changes.

At present, two main classes of methods are employed for predicting data with seasonal characteristics. The first class is the traditional statistical models, such as seasonal autoregressive integrated moving average (SARIMA) $[10,11]$ and Holt-Winters model [12]. The second class is artificial intelligence models, such as support vector machines [13] and neural network [14]. The genetic algorithm with multivariable grey model is effective when the data size is big [15]. In the present study, we eliminated the data fluctuations by grey cumulative generation and then developed a grey seasonal model (GSM). By comparing, our procedures outperform SARIMA and HoltWinters model.

The remainder of this paper is organized as follows. The forecasting method is introduced in Section 2. The data source and case analysis are presented in Section 3. The conclusion is given in Section 4.

\section{Grey Seasonal Model}

The data varied substantially among different seasons, but the traditional grey prediction model is only suitable for time series that exhibits an exponential trend, so it is not capable of effectively predicting data with large fluctuations [16]. Thus, in order to eliminate the fluctuations in the data and enhance the forecasting performance, the seasonal data are summarized into annual data in this study. The annual data are predicted by using $\operatorname{GM}(1,1)$ with fractional order accumulation [17-19]. The quarterly data are then restored by using the seasonal factors.

The original quarterly data are $X^{(0)}=\left\{x^{(0)}(1)\right.$, $\left.x^{(0)}(2), \ldots, x^{(0)}(n)\right\}$ with a cycle of $L$, and the modeling process for the GSM is as follows.

Step 1. If the size of the original quarterly data is big, then the size of the yearly data is small. Grey forecasting model is suitable. The yearly data sequence is

$$
Y^{(0)}=\left\{y^{(0)}(1), y^{(0)}(2), \ldots, y^{(0)}(m)\right\}, \quad m=\left[\frac{n}{L}\right],
$$

where $L$ is the size of a cycle, $n$ is the size of original quarterly data, and $m$ is the size of original yearly data.

$$
\begin{aligned}
y^{(0)}(1) & =\sum_{i=1}^{L} x^{(0)}(i), y^{(0)}(2)=\sum_{i=L+1}^{2 L} x^{(0)}(i), \ldots, y^{(0)}(m) \\
& =\sum_{i=(m-1) L+1}^{m L} x^{(0)}(i) .
\end{aligned}
$$

Step 2. The yearly data are accumulated to dig the potential rule. By using $y^{(r)}(k)=\sum_{j=1}^{k} C_{k-j+r-1}^{k-j} y^{(0)}(j)$, the r-order accumulation sequence is

$$
Y^{(r)}=\left\{y^{(r)}(1), y^{(r)}(2), \ldots, y^{(r)}(m)\right\},
$$

where $C_{r-1}^{0}=1, C_{k}^{k+1}=0, C_{k-j+r-1}^{k-j}=((k-j+r-1)(k-j+$ $r-2), \ldots,(r+1) r /(k-j) !)[20,21]$.

Step 3. For the $r$-order accumulation sequence $Y^{(r)}$, according to the modeling step of grey forecasting theory, the first-order differential equation with one variable (i.e., the $\operatorname{FGM}(1,1)$ model) can be expressed as

$$
\frac{\mathrm{d} y^{(r)}}{\mathrm{d} t}+a y^{(r)}=b,
$$

where $a$ is the development coefficient and $b$ is the grey action quantity. The solution to equation (4) is

$$
y^{(r)}(t+1)=\left(y^{(0)}(1)-\frac{b}{a}\right) e^{-a t}+\frac{b}{a} .
$$

The least squares estimate minimizes the sum of the squared residuals, so the parameters are obtained by using the least squares method. The unknown parameters $\widehat{a}$ and $\vec{b}$ can be solved by using the following formula:

$$
\left[\begin{array}{l}
\hat{a} \\
\widehat{b}
\end{array}\right]=\left(B^{T} B\right)^{-1} B^{T} Y,
$$

where 

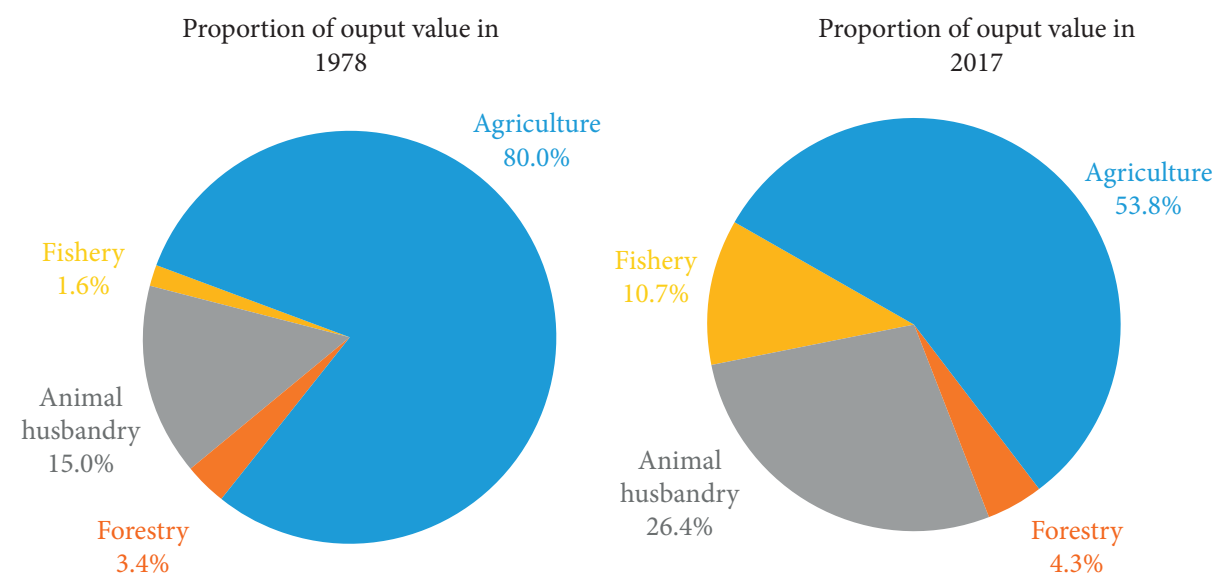

Figure 1: Change in the output value of agriculture, forestry, animal husbandry, and fishery during 1978-2017.

$$
\begin{aligned}
& B=\left[\begin{array}{cc}
-0.5\left(y^{(r)}(1)+y^{(r)}(2)\right) & 1 \\
-0.5\left(y^{(r)}(2)+y^{(r)}(3)\right) & 1 \\
\vdots & \vdots \\
-0.5\left(y^{(r)}(m-1)+y^{(r)}(m)\right) & 1
\end{array}\right], \\
& Y=\left[\begin{array}{c}
y^{(r)}(2) \\
y^{(r)}(3) \\
\vdots \\
y^{(r)}(m)
\end{array}\right] .
\end{aligned}
$$

Step 4. For the $r$-order accumulation sequence $Y^{(r)}$, according to the modeling step of grey forecasting theory, the time response function with $\widehat{a}$ and $\widehat{b}$ is

$$
\widehat{y}^{(r)}(k+1)=\left(y^{(0)}(1)-\frac{\widehat{b}}{\hat{a}}\right) e^{-\widehat{a} k}+\frac{\widehat{b}}{\widehat{a}}
$$

and $\hat{y}^{(r)}(k+1)$ is the fitting value at time $k+1$ [22].

Step 5. For $\widehat{Y}^{(r)}=\left\{\widehat{y}^{(r)}(1), \hat{y}^{(r)}(2), \ldots, \hat{y}^{(r)}(m), \ldots\right\}$, the predicted yearly data sequence is

$$
\alpha^{(r)} \widehat{Y}^{(r)}=\left\{\alpha^{(1)} \hat{y}^{(r)(1-r)}(1), \alpha^{(1)} \hat{y}^{(r)(1-r)}(2), \ldots, \alpha^{(1)} \hat{y}^{(r)(1-r)}(m), \alpha^{(1)} \hat{y}^{(r)(1-r)}(m+1), \ldots\right\}
$$

where $\quad \alpha^{(1)} \hat{y}^{(r)(1-r)}(k)=\hat{y}^{(r)(1-r)}(k)-\hat{y}^{(r)(1-r)}(k-1)$. Then, the forecasting value is

$$
\hat{y}^{(0)}(1), \hat{y}^{(0)}(2), \ldots, \hat{y}^{(0)}(m), \hat{y}^{(0)}(m+1), \hat{y}^{(0)}(m+2), \ldots
$$

Step 6. To obtain the predicted quarterly data, the seasonal factor $S_{i}(i=1,2, \ldots, L)$ is calculated by using the corresponding period average method [23]:

$$
S_{i}=\frac{\bar{x}_{i}^{(0)}(i)}{\bar{x}^{(0)}},
$$

where $\bar{x}_{i}^{(0)}(i)$ indicates the average of quarter $i$ (at time point $i)$ and $\bar{x}^{(0)}$ represents the average of all quarters.

Step 7. For the predicted quarterly data sequence $\widehat{X}^{(0)}=\left\{\widehat{x}^{(0)}(1), \widehat{x}^{(0)}(1), \widehat{x}^{(0)}(2), \ldots, \widehat{x}^{(0)}(n), \widehat{x}^{(0)}(n+1), \ldots\right\}$,

where $\hat{x}^{(0)}(1)=\hat{y}^{(0)}(1)\left(S_{1} / L\right), \hat{x}^{(0)}(2)=\hat{y}^{(0)}(1)\left(S_{2} / L\right), \ldots$, $\hat{x}^{(0)}(L)=\hat{y}^{(0)}(1)\left(S_{L} / L\right)$,

$$
\hat{x}^{(0)}(L+1)=\hat{y}^{(0)}(2) \frac{S_{L+1}}{L}, \ldots, \hat{x}^{(0)}(n)
$$

$$
=\widehat{y}^{(0)}(m) \frac{S_{n}}{L}, \ldots, \widehat{x}^{(0)}(n+1)
$$

$$
=\widehat{y}^{(0)}(m+1) \frac{S_{n+1}}{L}, \ldots
$$

Thus, we can obtain the predicted quarterly data.

Step 8. To evaluate the model, the mean absolute percentage error (MAPE) is calculated as follows:

$$
\text { MAPE }=\frac{1}{n} \sum_{k=1}^{n}\left|\frac{\widehat{x}^{(0)}(k)-x^{(0)}(k)}{x^{(0)}(k)}\right| \times 100 \% .
$$

\section{Data Source and Forecasting Analysis}

According to the "Circular of the National Bureau of Statistics on the Implementation of the National Standards for the Classification of New National Economic Industries," the new version of the "Classification of National Economic Industries" was implemented in 2012. Thus, the quarterly 
output values for agriculture, forestry, animal husbandry, and fishery from 2012 to 2017 are from the National Bureau of Statistics (http://www.stats.gov.cn/). The quarterly output values in 2012-2017 are shown in Figure 2.

According to Figure 2, obvious periodic variations occurred in the output values for agriculture, forestry, animal husbandry, and fishery. Taking the fishery as an example, the quarterly output value for fishery during 2012-2017 is shown in Table 1. A GSM is established to predict the quarterly output value during 2018-2021.

The annual output value is predicted by using the $\operatorname{GM}(1,1)$ with fractional order accumulation. The MAPE is the smallest obtained by the particle swarm optimization in MATLAB 2016. The fitting precision is high according to the MAPE criterion [2]. The fitting and prediction results for the annual output value during 2012-2021 are shown in Table 2.

The seasonal factor for fishery is calculated by using the corresponding period average method (equation (11)). The results are shown in Table 3.

The fitting value for fishery is determined by using equation (12), and the results are shown in Table 4. To highlight the applicability and accuracy of the proposed model, fitting results are also obtained by using the HoltWinters model, SARIMA model, and the seasonal discrete grey model (SDGM).

In Table 4, the MAPE of the GSM is significantly lower than those produced by the Holt-Winters model, SARIMA model, and SDGM model. It indicated that the GSM can obtain more accurate prediction, and it is better at representing the variation of seasonal data. Thus, it provides a new method for predicting the seasonal data. Therefore, the quarterly output value for fishery from 2018 to 2021 is predicted by using the GSM. The results are shown in Table 5, and the variable trends are presented in Figure 3.

As shown in Table 5 and Figure 3, the predicted output value for fishery increased in all quarters with relatively slow increases in Q1-Q3, but a dramatic increase in Q4. The improvement in the annual output value for fishery is mainly due to major reformation of the production methods for aquatic products. The increase in the output value of fish farming was greater than that of catching fish. Thus, aquaculture accounted for most of the growth in aquatic products. Great efforts have been made to strengthen the conservation and sustainable utilization of aquatic resources, and standardized and intensive farming modes have developed to facilitate the rapid development of the fishery industry [24].

The catching fish is still an important part of the fishery in China, and in order to protect fishery resources and biodiversity, China enforced summer-fishing moratorium in the ocean since 1995 and spring-fishing-ban in the Yangtze River since 2003. The summer-fishing-ban season in the ocean mainly occurs in the second and third quarters, and the spring-fishing-ban season in the Yangtze River mainly happens in the first and second quarters. They also contribute to the high seasonal discrepancies in the fishery output value. The slow increases in the fishery output value in Q1-Q3 are the results of the biodiversity conservation and the ecological balance, as well as the protection of resources.

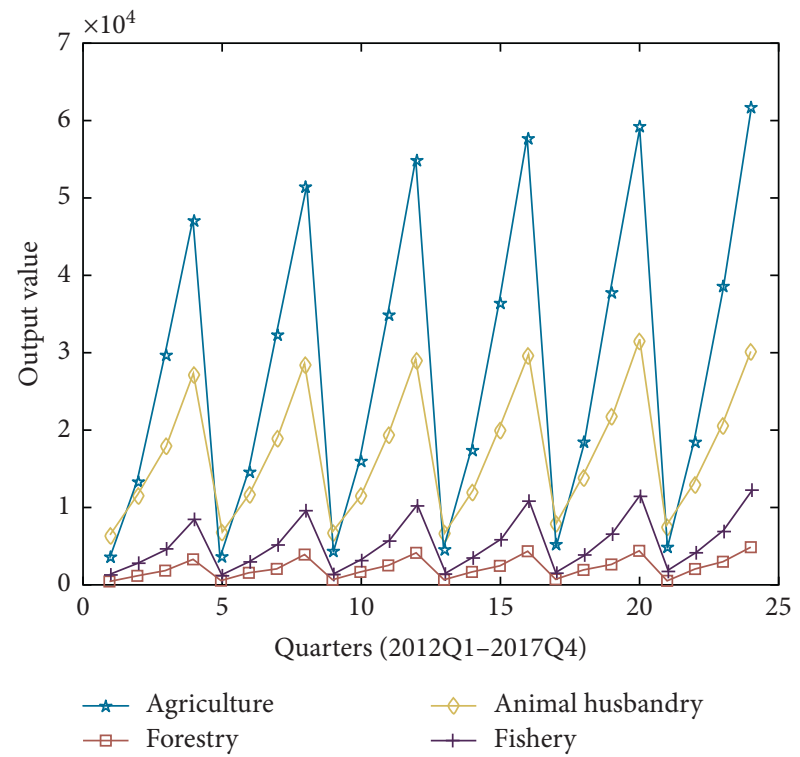

FIGURE 2: Quarterly output values for agriculture, forestry, animal husbandry, and fishery in 2012-2017.

Similarly, the output values for agriculture, forestry, and animal husbandry, as well as the total output value are predicted, respectively. The forecasting results and variable trends are shown in Table 6 and Figures 4-7.

The output values for agriculture, forestry, and animal husbandry, as well as their total output value have seasonal variation and fluctuated increase over the four quarters.

The yearly increases and steady development of the agricultural output value can be explained by the following three reasons. Firstly, the state has supported the construction of agricultural infrastructure by focusing on irrigation and water conservation. Secondly, the state implemented the subsidy policy for the purchase of agricultural machine and tool to promote the development of agricultural mechanization. Thirdly, the state has consolidated the driving effects of agricultural scientific and technological innovation, and thus agricultural scientific and technological progress have become increasingly apparent. Therefore, crops are more resistant to natural disasters, extreme weather, diseases and pests, industrial pollution, and manmade accidents. The agricultural output value has increased steadily.

In addition to the steady increases in the output value during each year, the variations in the agricultural output value also exhibited significant seasonal characteristics. As shown in Figure 4, the agricultural output value increased slowly and gradually stabilized in Q1-Q2, whereas it exhibited relatively rapid growth in Q3-Q4. Seasonal changes show an important impact of agricultural development. Spring planting and autumn harvesting is the agricultural season rule in most grain-producing areas of China. The major crops are sown and grown in the spring and summer. The mature agricultural products are mainly harvested in the fall and sold in the winter, so the agricultural output value is generally low in Q1-Q2 but high in Q3-Q4. 


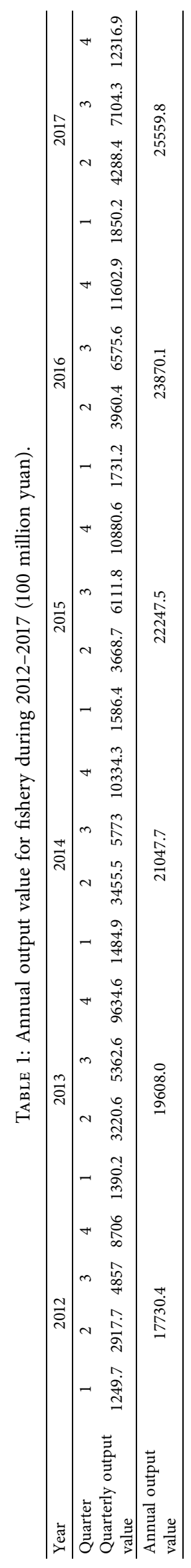


TABLE 2: Fitting and forecasting results of the annual output value for fishery (100 million yuan).

\begin{tabular}{lcc}
\hline Year & Actual value & Fitting value \\
\hline 2012 & 17730.4 & 17730.4 \\
2013 & 19608.0 & 19606.2 \\
2014 & 21047.7 & 20937.9 \\
2015 & 22247.5 & 22360.2 \\
2016 & 23870.1 & 23879.0 \\
2017 & 25559.8 & 25501.1 \\
MAPE & & 0.22 \\
2018 & & 27233.3 \\
2019 & & 29083.1 \\
2020 & & 31058.7 \\
2021 & & 33168.4 \\
\hline
\end{tabular}

TABLE 3: Seasonal factors for fishery.

\begin{tabular}{lcr}
\hline Quarter & Seasonal factor & Seasonal factor/4 \\
\hline 1 & 0.29 & 0.07 \\
2 & 0.66 & 0.17 \\
3 & 1.10 & 0.28 \\
4 & 1.95 & 0.49 \\
\hline
\end{tabular}

TABLE 4: Fitting results of the GSM, Holt-Winters model, and SARIMA model (100 million yuan).

\begin{tabular}{|c|c|c|c|c|c|c|}
\hline Year & Quarter & Actual value & GSM value & Holt-Winters value & SARIMA value & SDGM \\
\hline \multirow{4}{*}{2012} & 1 & 1249.7 & 1266.8 & 1249.7 & 1249.7 & \\
\hline & 2 & 2917.7 & 2932.4 & 2917.7 & 2917.7 & \\
\hline & 3 & 4857.0 & 4878.2 & 4857.0 & 4857.0 & \\
\hline & 4 & 8706.0 & 8653.0 & 8706.0 & 8706.0 & \\
\hline \multirow{4}{*}{2013} & 1 & 1390.2 & 1400.8 & 1390.2 & 1324.8 & 1390.20 \\
\hline & 2 & 3220.6 & 3242.7 & 972.0 & 3226.4 & 3140.22 \\
\hline & 3 & 5362.6 & 5394.2 & 5362.6 & 5344.8 & 5094.93 \\
\hline & 4 & 9634.6 & 9568.5 & 9730.9 & 9416.4 & 8911.22 \\
\hline \multirow{4}{*}{2014} & 1 & 1484.9 & 1495.9 & 1484.6 & 1562.0 & 1066.81 \\
\hline & 2 & 3455.5 & 3462.9 & 3415.2 & 3471.7 & 3178.07 \\
\hline & 3 & 5773.0 & 5760.6 & 5868.0 & 5801.3 & 5469.01 \\
\hline & 4 & 10334.3 & 10218.4 & 10462.9 & 10354.5 & 9757.43 \\
\hline \multirow{4}{*}{2015} & 1 & 1586.4 & 1597.6 & 1589.9 & 1610.2 & 1302.39 \\
\hline & 2 & 3668.7 & 3698.2 & 3643.2 & 3733.6 & 3551.56 \\
\hline & 3 & 6111.8 & 6151.9 & 6222.0 & 6199.0 & 6036.10 \\
\hline & 4 & 10880.6 & 10912.5 & 11062.1 & 11012.5 & 10656.68 \\
\hline \multirow{4}{*}{2016} & 1 & 1731.2 & 1706.1 & 1672.0 & 1665.7 & 1745.19 \\
\hline & 2 & 3960.4 & 3949.4 & 3964.9 & 4007.5 & 4063.07 \\
\hline & 3 & 6575.6 & 6569.8 & 6708.6 & 6575.7 & 6604.64 \\
\hline & 4 & 11602.9 & 11653.8 & 11885.7 & 11555.3 & 11324.88 \\
\hline \multirow{4}{*}{2017} & 1 & 1850.2 & 1822.0 & 1781.1 & 1847.4 & 1855.38 \\
\hline & 2 & 4288.4 & 4217.6 & 4231.7 & 4292.8 & 4368.11 \\
\hline & 3 & 7104.3 & 7016.1 & 7251.4 & 7051.4 & 7068.99 \\
\hline & 4 & 12316.9 & 12445.4 & 12825.1 & 12295.9 & 12000.87 \\
\hline MAPE & & $0.75 \%$ & $5.19 \%$ & $1.31 \%$ & $4.89 \%$ & \\
\hline
\end{tabular}

The output value for forestry is characterized by a higher output value in Q4 and lower output values in Q1-Q3. The growth rates in all four quarters are comparable. The yearly output value is increased gradually. The increased output value for forestry can mainly be explained by the implementation of policies and economic development. The comprehensive reform of state-owned forests right and collective forest right in China bring the rapid development of the forestry industry and rapid increases in forest product outputs. In addition, the Eighteenth National Congress of the Communist Party of China promoted the construction of an ecological civilization by assigning the same level of 
TABLE 5: Forecasting results of fishery for the GSM (100 million yuan).

\begin{tabular}{|c|c|c|c|c|}
\hline \multirow{2}{*}{ Quarter } & \multicolumn{4}{|c|}{ Year } \\
\hline & 2018 & 2019 & 2020 & 2021 \\
\hline 1 & 1945.7 & 2077.9 & 2219.0 & 2369.8 \\
\hline 2 & 4504.1 & 4810.1 & 5136.8 & 5485.7 \\
\hline 3 & 7492.7 & 8001.6 & 8545.2 & 9125.6 \\
\hline 4 & 13290.7 & 14193.5 & 15157.7 & 16187.3 \\
\hline
\end{tabular}

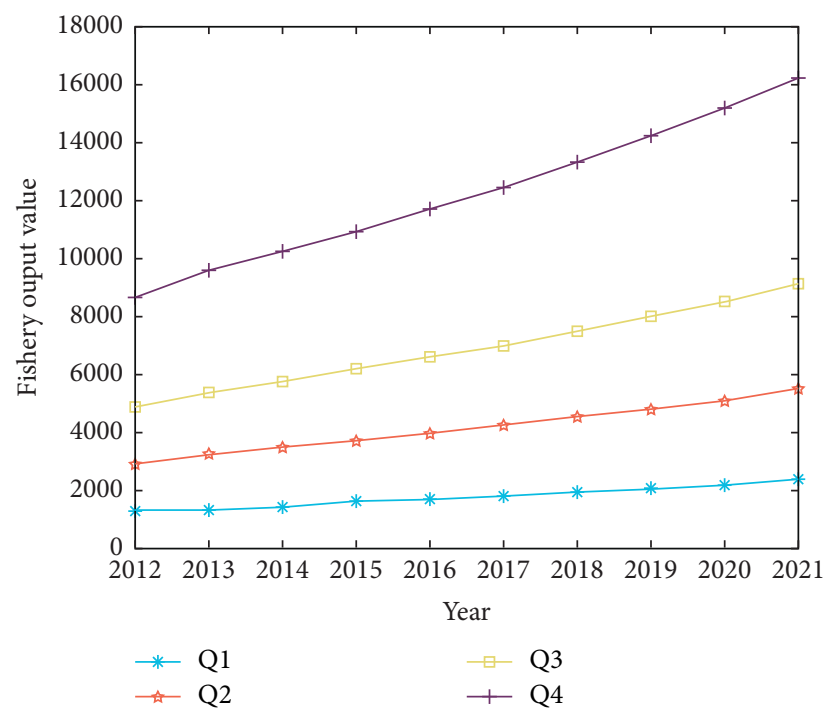

FIGURE 3: Variable trends in the quarterly output value for fishery.

TABLE 6: Forecasting results of agriculture, forestry, animal husbandry, and the total output value (100 million yuan).

\begin{tabular}{|c|c|c|c|c|c|}
\hline Year & Quarter & Agriculture & Forestry & Animal husbandry & Total output value \\
\hline \multirow{4}{*}{2018} & 1 & 5051.3 & 781.1 & 7409.1 & 16186.5 \\
\hline & 2 & 18630.5 & 2110.0 & 13013.4 & 40226.3 \\
\hline & 3 & 39775.9 & 3110.6 & 21028.4 & 74791.0 \\
\hline & 4 & 62896.0 & 5287.2 & 31153.6 & 117787.2 \\
\hline \multirow{4}{*}{2019} & 1 & 5125.6 & 826.6 & 7481.1 & 16510.7 \\
\hline & 2 & 18904.5 & 2233.0 & 13140.0 & 41032.0 \\
\hline & 3 & 40360.7 & 3292.0 & 21233.0 & 76288.9 \\
\hline & 4 & 63820.9 & 5595.6 & 31456.7 & 120146.1 \\
\hline \multirow{4}{*}{2020} & 1 & 5178.9 & 874.4 & 7539.9 & 16777.6 \\
\hline & 2 & 19101.1 & 2362.1 & 13243.2 & 41695.3 \\
\hline & 3 & 40780.6 & 3482.3 & 21399.8 & 77522.2 \\
\hline & 4 & 64484.8 & 5919.0 & 31703.9 & 122088.6 \\
\hline \multirow{4}{*}{2021} & 1 & 5216.2 & 924.6 & 7587.8 & 16997.0 \\
\hline & 2 & 19238.5 & 2497.7 & 13327.4 & 42240.5 \\
\hline & 3 & 41073.9 & 3682.1 & 21535.9 & 78535.9 \\
\hline & 4 & 64948.6 & 6258.7 & 31905.4 & 123685.0 \\
\hline
\end{tabular}

importance to economic construction, political construction, cultural construction, and social construction. Hence, the ecological construction of forestry has entered a new historical stage. The activity of voluntary planting tree, the key engineering construction for forestry, and the Green for Grain program have gradually enhanced the ecological protection and restoration. The output value for forestry will effectively increase. Furthermore, due to the fast growth of the national economy and the accelerated urbanization in China, as the basic material, the demand of forest products for construction has also increased.

Similar to other industries, the output value for animal husbandry has also increased steadily. Animal husbandry is an important component of agriculture. The outputs and 


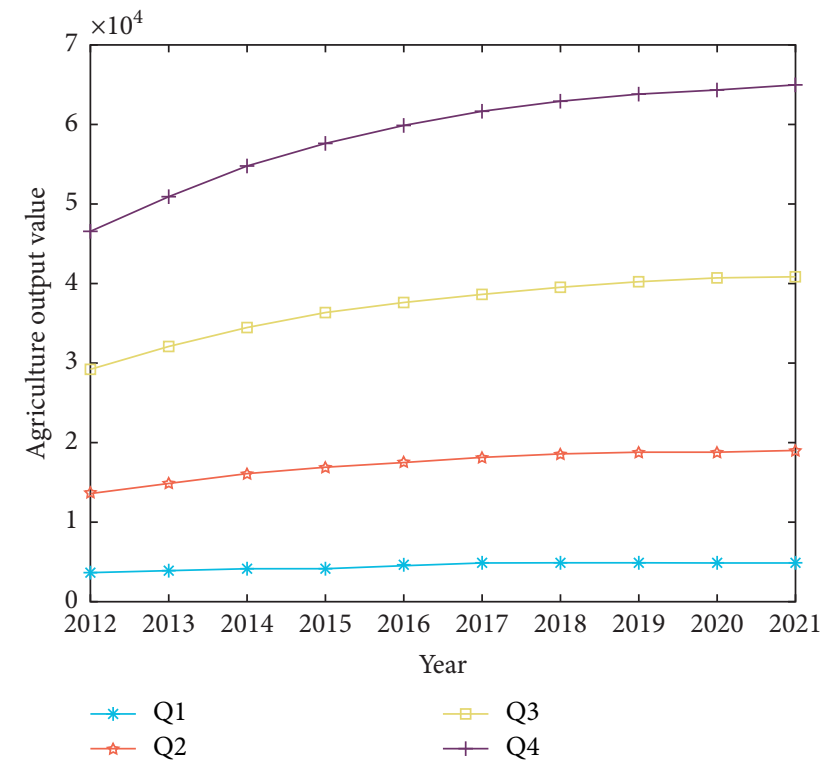

Figure 4: Variable trends in the quarterly output value for agriculture.

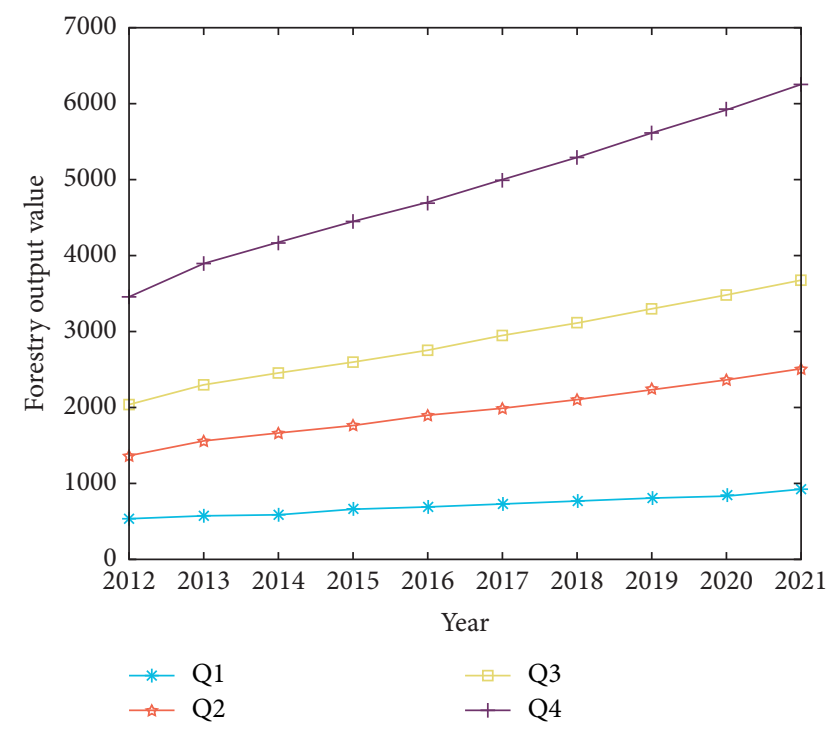

FIGURE 5: Variable trends in the quarterly output value for forestry.

growth rates for livestock and poultry products directly reflect the development and structural adjustment of the animal husbandry. The consumption of livestock and poultry products is indispensable to people's daily life. The supply of livestock and poultry products has been affected by the development of urbanization and the optimization of dietary structure. The increased incomes of urban and rural residents have transformed and upgraded the consumption level and structure. The demand of livestock and poultry products has particularly increased. It promotes the rapid development of the livestock breeding industry and the rapid increase in the output value for animal husbandry. China's output of livestock and poultry ranks first in the world. However, as shown in Figure 6, the increase rates in the

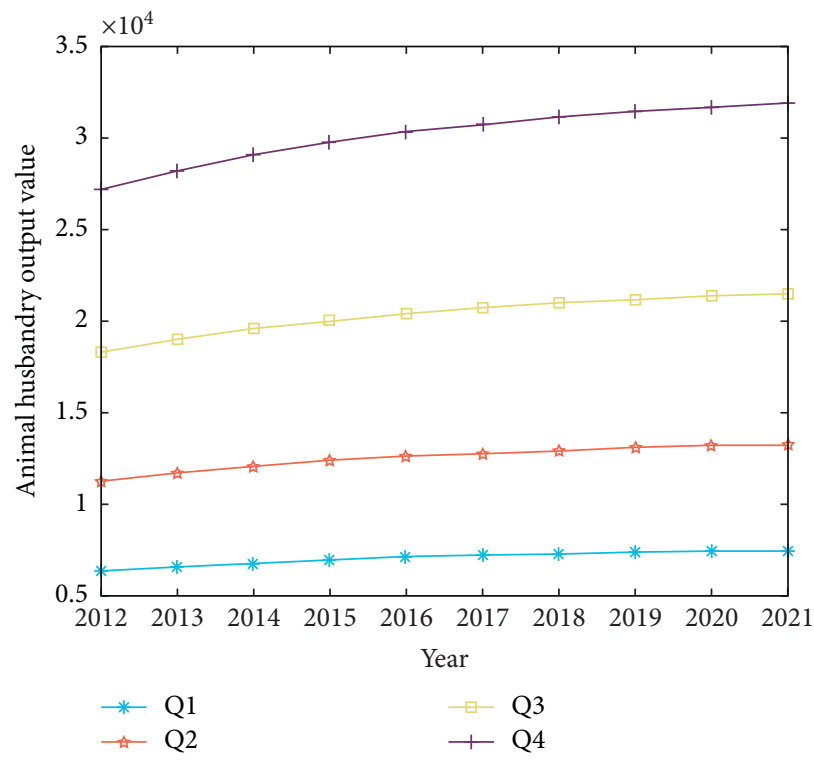

FIgURE 6: Variable trends in the quarterly output value for animal husbandry.

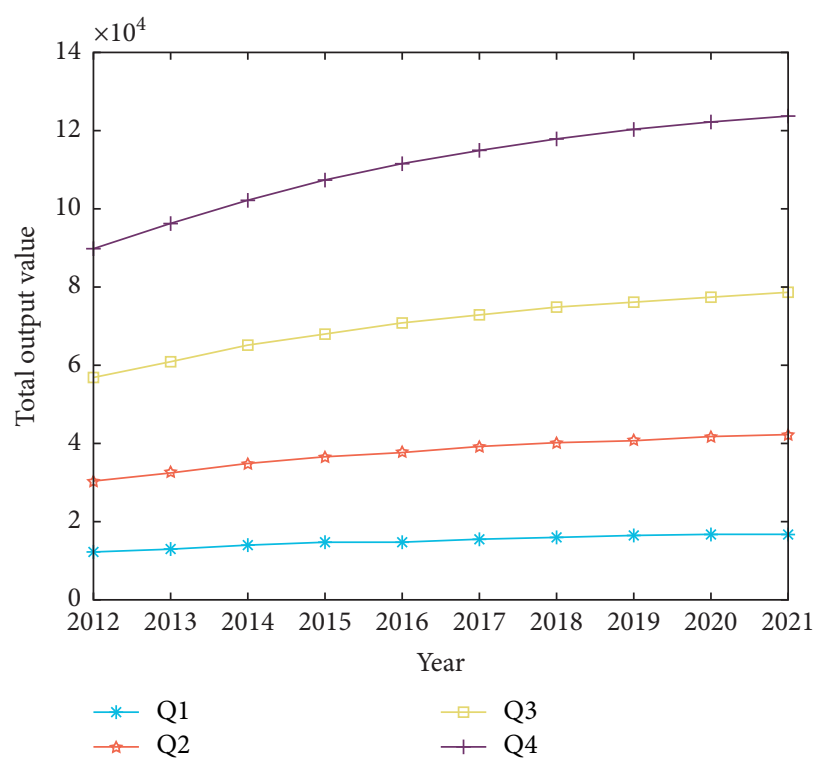

FIGURE 7: Variable trends in the total quarterly output value for agriculture, forestry, animal husbandry, and fishery.

animal husbandry output during 2018-2021 are slower than those during 2012-1017, which suggests that the development of the animal husbandry has been somewhat restricted. The development of the animal husbandry is highly dependent on the environment, but the rigid requirements for environmental protection and the constraints on land resources in recent years have led to the gradual enlargement of the no animal husbandry zones. So, the output value for animal husbandry has also been affected to some extent.

Due to the increased output values for each industry, the total output value for agriculture, forestry, animal husbandry, and fishery has also increased. In the new normal 
economy, economic transformation and upgrading are essential for all industries. The total output value has steadily increased, which is an important consequence of the structural adjustment and optimization. The agriculture, forestry, animal husbandry, and fishery should grasp the new opportunities for development, deal with the possible risks leisurely, and improve the efficiency and quality of development.

\section{Conclusion}

The forecasting results demonstrated the increasing trends in the output values for agriculture, forestry, animal husbandry, and fishery, as well as their total output value in the next four years. This is consistent with the actual situation. Because Chinese government recently released a rural vitalization strategy for 2018-2022 to promote poverty reduction and rural development, it implied that the agricultural economy in China is sustainable and desirable.

Our results indicated that the GSM greatly improved the forecasting accuracy. The GSM can be employed for predicting the other seasonal time series, such as the monthly agricultural output values and the prices of agricultural products, in order to determine the effectiveness and adaptability of this model.

GSM is a single variable model. Because grey model is suitable for the forecasting problem with a smaller size sample, GSM can obtain better results when the data size is smaller. When the data size is big, GSM is not suitable. This is the limitation of GSM. It is suggested to address this problem in the future.

\section{Data Availability}

The data and computation code used to support the findings of this study are available from the corresponding author upon request.

\section{Conflicts of Interest}

The authors declare that there are no conflicts of interest regarding the publication of this paper.

\section{Acknowledgments}

This research was supported by the National Natural Science Foundation of China (71871084), the Excellent Young Scientist Foundation of Hebei Education Department (SLRC2019001), and The Project of High-Level Talent in Hebei Province.

\section{References}

[1] S.-Z. Han, W.-T. Pan, Y.-Y. Zhou et al., "Construct the prediction model for China agricultural output value based on the optimization neural network of fruit fly optimization algorithm," Future Generation Computer Systems, vol. 86, pp. 663-669, 2018.

[2] Y.-S. Liu and W.-Y. Liu, "Forecasting value of agricultural imports using a novel two-stage hybrid model," Computers and Electronics in Agriculture, vol. 104, pp. 71-83, 2014.
[3] F. Doblas-Reyes, R. Hagedorn, and T. Palmer, "Developments in dynamical seasonal forecasting relevant to agricultural management," Climate Research, vol. 33, pp. 19-26, 2006.

[4] S.-L. Ou, "Forecasting agricultural output with an improved grey forecasting model based on the genetic algorithm," Computers and Electronics in Agriculture, vol. 85, pp. 33-39, 2012.

[5] L. Liu, Y. Wang, J. Wu, J. Wang, and C. Xi, "New optimized grey derivative models for grain production forecasting in China," The Journal of Agricultural Science, vol. 153, no. 2, pp. 257-269, 2015.

[6] Z. F. Xi, "Development course, current situation and forecast of green agriculture in China," Reformation \& Strategy, vol. 32, no. 12, pp. 94-102, 2016.

[7] C. Z. Ma, J. F. Deng, Y. W. Wei et al., "Analysis and forecast of agricultural industrial structure of Liaoning Province based on grey theory," Journal of Northeast Agricultural Sciences, vol. 41, no. 4, pp. 106-112, 2016.

[8] X. B. Yu, T. X. Yao, X. Luo et al., "Integrate NARX neural network and grey system to forecast China agricultural areas affected by natural disasters," Journal of Arid Land Resources and Environment, vol. 30, no. 9, pp. 64-70, 2016.

[9] G. S. Zhao, H. W. Zhang, A. H. Liu et al., "Prediction and analysis of agricultural irrigation water in China based on grey GM $(1,1)$ model with equal dimension," Mathematics in Practice and Theory, vol. 48, no. 4, pp. 299-304, 2018.

[10] P. Ramos, N. Santos, and R. Rebelo, "Performance of state space and ARIMA models for consumer retail sales forecasting," Robotics and Computer-Integrated Manufacturing, vol. 34, pp. 151-163, 2015.

[11] S. Moisan, R. Herrera, and A. Clements, "A dynamic multiple equation approach for forecasting PM2.5 pollution in Santiago, Chile," International Journal of Forecasting, vol. 34, no. 4 , pp. 566-581, 2018.

[12] L. F. Tratar and E. Strmčnik, "The comparison of HoltWinters method and multiple regression method: a case study," Energy, vol. 109, pp. 266-276, 2016.

[13] Y. Zhou, F.-J. Chang, L.-C. Chang, I.-F. Kao, Y.-S. Wang, and C.-C. Kang, "Multi-output support vector machine for regional multi-step-ahead PM2.5 forecasting," Science of The Total Environment, vol. 651, no. 1, pp. 230-240, 2019.

[14] G. Kao, B. Uniejewski, and R. Weron, "On the importance of the long-term seasonal component in day-ahead electricity price forecasting with NARX neural networks," International Journal of Forecasting, vol. 35, no. 4, pp. 1520-1532, 2019.

[15] T. Ozcan, "Application of seasonal and multivariable gray prediction models for short-term load forecasting," Alphanumeric Journal, vol. 5, no. 2, pp. 329-338, 2017.

[16] M. Zhou, Bo Zeng, and W. Zhou, "A hybrid grey prediction model for small oscillation sequence based on information decomposition," Complexity, vol. 2020, Article ID 5071267, 13 pages, 2020.

[17] B. Zeng, M. Zhou, X. Liu, and Z. Zhang, “Application of a new grey prediction model and grey average weakening buffer operator to forecast China's shale gas output," Energy Reports, vol. 6, no. 6, pp. 1608-1618, 2020.

[18] Y. Chen, W. Lifeng, L. Lianyi, and Z. Kai, "Fractional Hausdorff grey model and its properties," Chaos, Solitons \& Fractals, vol. 138, p. 109915, 2020.

[19] X. Xiao, H. Duan, and J. Wen, “A novel car-following inertia gray model and its application in forecasting short-term traffic flow," Applied Mathematical Modelling, vol. 87, pp. 546-570, 2020.

[20] L. Wu, S. Liu, L. Yao, S. Yan, and D. Liu, "Grey system model with the fractional order accumulation," Communications in 
Nonlinear Science and Numerical Simulation, vol. 18, no. 7, pp. 1775-1785, 2013.

[21] L. Liu and L. Wu, "Holt-Winters model with grey generating operator and its application," Communications in StatisticsTheory and Methods, vol. 49, p. 1, 2020.

[22] B. Zeng, M. Tong, and X. Ma, "A new-structure grey Verhulst model: development and performance comparison," Applied Mathematical Modelling, vol. 81, no. 81, pp. 522-537, 2020.

[23] M. R. Xiang, Q. H. Wang, and D. Ma, Statistical, Machinery Industry Press, Beijing, China, 2014.

[24] National Bureau of Statistics, 2011, http://www.gov.cn/gzdt/ 2011-03/09/content_1820817.htm.

[25] A. Rehman, L. Jingdong, A. A. Chandio, and I. Hussain, "Livestock production and population census in Pakistan: determining their relationship with agricultural GDP using econometric analysis," Information Processing in Agriculture, vol. 4, no. 2, pp. 168-177, 2017. 